\title{
CLASSIFICATION OF COARSE SOILS BASED ON ENGINEERING PROPERTIES
}

\author{
Kano Ueshita* and KazUmasa NonOGaKI**
}

\begin{abstract}
The authors studied the classification system for coarse soils based on the maximum dry density and the optimum moisture content of the modified AASHO compaction test, the soaked CBR at 95 percent of the maximum dry density, and the coefficient of permeability of compacted soils. After this study, the best boundaries between clean gravels or sands, gravels or sands with some fines, gravels or sands with fines, and fine soils were found to be $5 \%, 15 \%$ and $50 \%$, respectively. And the criteria of well-graded gravels or sands were found to be the coefficient of uniformity $C_{u}$ greater than 10 and the coefficient of curvature $C_{z}$ between 1 and $\sqrt{C_{u}}$.

Based on these considerations, the authors proposed a modification of the Unified Soil Classification System using the above-mentioned criteria and $2.0 \mathrm{~mm}$ for the gravel-sand boundary, and showed the relationships between the engineering properties and the modified classification system for coarse soils.
\end{abstract}

Key Words: California Bearing Ratio, compaction, grain size distribution, gravel, laboratory test, permeability, sand, soil classification

IGC: $\quad$ D 1

\section{INTRODUCTION}

Nowadays, many agencies in Japan use the Unified Soil Classification System (USCS) in their study of soils for construction work.

This classification system was primarily proposed as the Airfield Classification System by Casagrande in 1942 and developed through active use by the U.S. Corps of Engineers and the U.S. Bureau of Reclamation. The American Society for Testing and Materials (ASTM) adopted this system as the "Standard Method for Classification of Soils for Engineering Purposes, ASTM Designation: D2487-69" in 1969.

In many countries, their modifications of the USCS have been adopted or proposed as. the standard classification systems, e.g. SNV 70005 (1959) in Switzerland, IS 1498 (1959), in. India, DIN 18196 (1970) in Germany, and the suggested British Soil Classification. System (the suggested BSCS) by Dumbleton (1968).

* Associate Professor, Dept. of Civil Engineering, Nagoya University.

** Research Assistant, Dept. of Civil Engineering, Nagoya University, Chikusa-ku, Nagoya. Written discussions on this paper should be submitted before July 1, 1972. 
Between the systems of ASTM, SNV, DIN and the suggested BSCS, there are several differences as follows: The gravel-sand boundary is $4.76 \mathrm{~mm}$ for ASTM, $2.4 \mathrm{~mm}$ for the suggested BSCS, and $2.0 \mathrm{~mm}$ for SNV and DIN. The classification boundaries between clean gravels or sands, gravels or sands with some fines, gravels or sands with fines, and fine soils are at $5 \%, 12 \%$ and $50 \%$ of fines for ASTM, 5\%,15\%,50\% for SNV, $5 \%$, $15 \%$ and $40 \%$ for DIN, and $5 \%, 20 \%$ and $50 \%$ for the suggested BSCS. The criterion for the well graded soils is that the coefficient of uniformity $C_{u}$ is greater than 4 for gravels and greater than 6 for sands after ASTM; $C_{u}$ is greater than 5 for gravels and sands after the suggested BSCS; or $C_{u}$ is greater than 6 for gravels and sands after DIN and also the coefficient of curvature $C_{z}$ is between 1 and 3 for gravels and sands.

The Japanese Society of Soil Mechanics and Foundation Engineering organized the Committee on Standardization of Identification and Classification of Soils in July, 1970 to establish the Japanese Unified Soil Classification System (the Japanese USCS). Since one of the authors, Ueshita, has been a member of this committee, the authors have done some experiments and also gathered data to establish the best criteria of engineering classification of soils.

In the following considerations, the USCS designated by ASTM is used, excepting that GM and SM soil groups are divided into GMd, GMu, SMd and SMu referring to the plasticity chart shown in Fig. 1 after the manner of highway and airfield engineers. Afterwards, a modified classification system is introduced as a conclusion of this study.

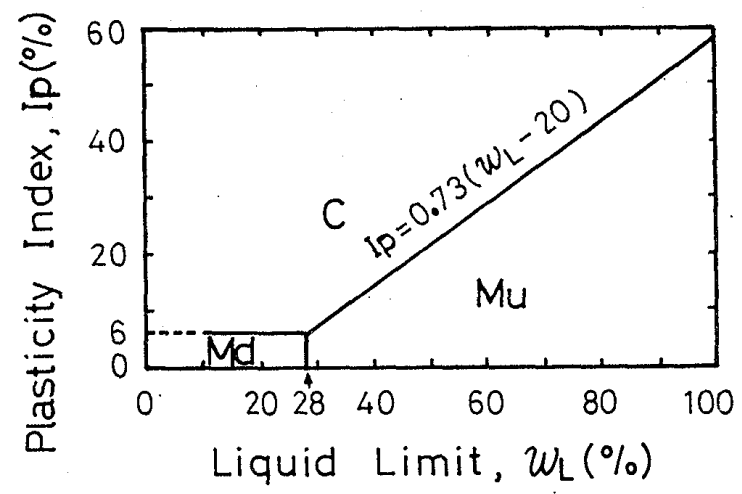

Fig. 1. Correspondence between the Symbols ( $\mathrm{Md}, \mathrm{Mu}$ and $\mathrm{C}$ ) and the Regions on the Plasticity Chart

\section{DIVISION BETWEEN GRAVEL AND SAND}

In the process of establishing the Japanese USCS, the division between gravel and sand is one of the difficult problems to decide. The $4.76 \mathrm{~mm}$ division is adopted in the USCS designated by ASTM, but in Japan the $2.0 \mathrm{~mm}$ division has been in use for a long time. The Intersociety Committee for the Standardization of Particle-Size Range in the U.S.A. recommended $2.0 \mathrm{~mm}$ for the upper sand size limit. But, the particles between $2.0 \mathrm{~mm}$ and $4.76 \mathrm{~mm}$ in size may be considered to have a similar character with sands finer than $2.0 \mathrm{~mm}$ rather than with gravels greater than $4.76 \mathrm{~mm}$ in size as shown 


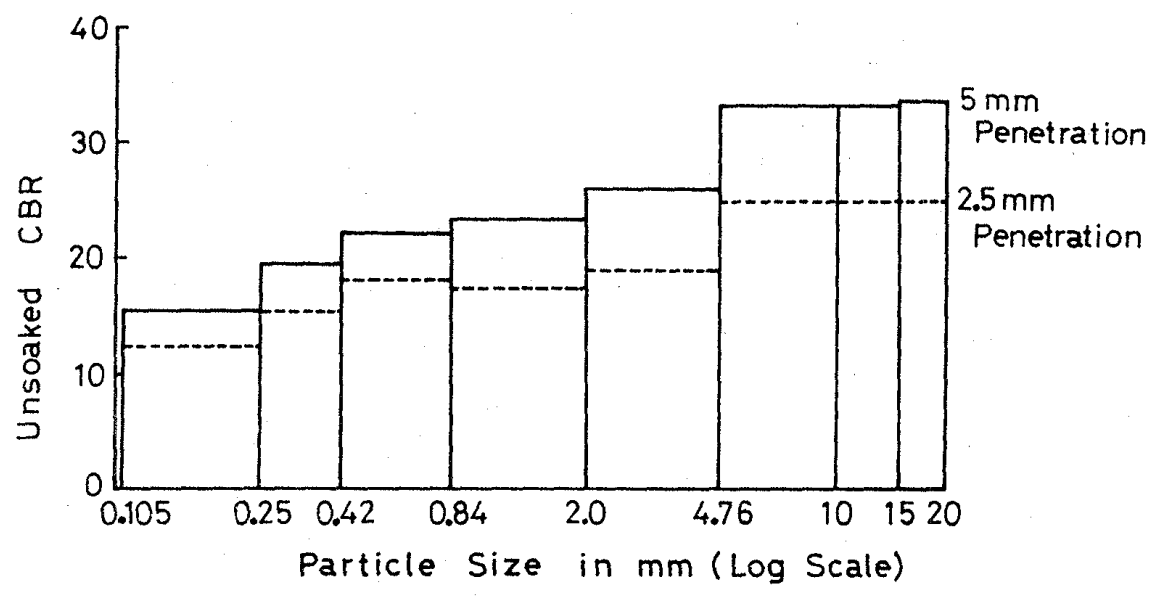

Fig. 2. Unsoaked CBR and Particle Size Ranges of Crushed Sandstone (After Imai (1970))

in Fig. 2 concerning the CBR of crushed aggregates of limited sizes.

The authors compared the correlations between the maximum dry density, the optimum moisture content or the CBR and the soil classifications in the cases of the $4.76 \mathrm{~mm}$ division and the $2.0 \mathrm{~mm}$ division for gravel and sand fractions. In the latter classification, only the gravel-sand boundary of $4.76 \mathrm{~mm}$ in the USCS was replaced by $2.0 \mathrm{~mm}$ and other criteria were not changed.

The results are shown by Figs. 3, 4 and 5. In Figs. 3(a) and 4(a), the results of the modified AASHO compaction test performed mainly in the Tókai district, Japan, were plotted. And in Fig. 5(a), the soaked CBR values at 95 percent density of the maximum were plotted. In drawing the Figs. 3(b), 4(b) and 5(b), those data that fell far out of the main distribution of points in Figs. 3(a), 4(a) and 5(a) were neglected.

In these figures, each soil group has wide ranges of engineering properties. The overlaps of the engineering properties of differently classified soils are noticeable rather than the differences between them.

By changing the gravel-sand boundary from $4.76 \mathrm{~mm}$ to $2.0 \mathrm{~mm}$, the relationships in the figures shift somewhat as follows: About 10 percent of data are transfered from S-soils to G-soils in the figures. In Fig. 3(b), the upper limits of the distributions for Ssoils and the lower limits for GP and GMd are decreased in some degree, and the upper limit for GMd is somewhat increased. The arithmetic mean values in the maximum dry density are shifted slightly. In Fig. 4(b), the upper limits of GMd and GMu are increased and the arithmetic mean values are shifted very slightly. In Fig. 5(b), the corresponding range of GMd becomes larger. The arithmetic mean values of CBR are not affected significantly except that of GP.

In these figures, it is difficult to choose the $4.76 \mathrm{~mm}$ boundary or the $2.0 \mathrm{~mm}$ boundary as a better criterion of dividing G-soils and S-soils in the USCS. 


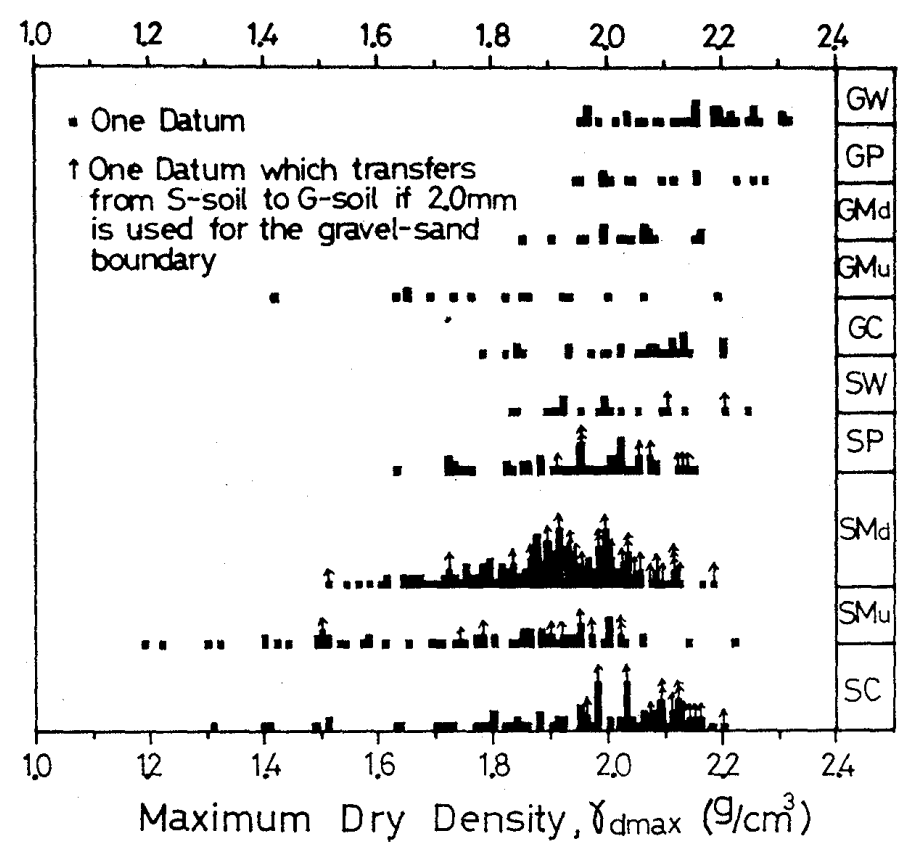

Fig. 3(a) Relationship between the Maximum Dry Density of the Modified AASHO Compaction Test and the Unified Soil Classification System

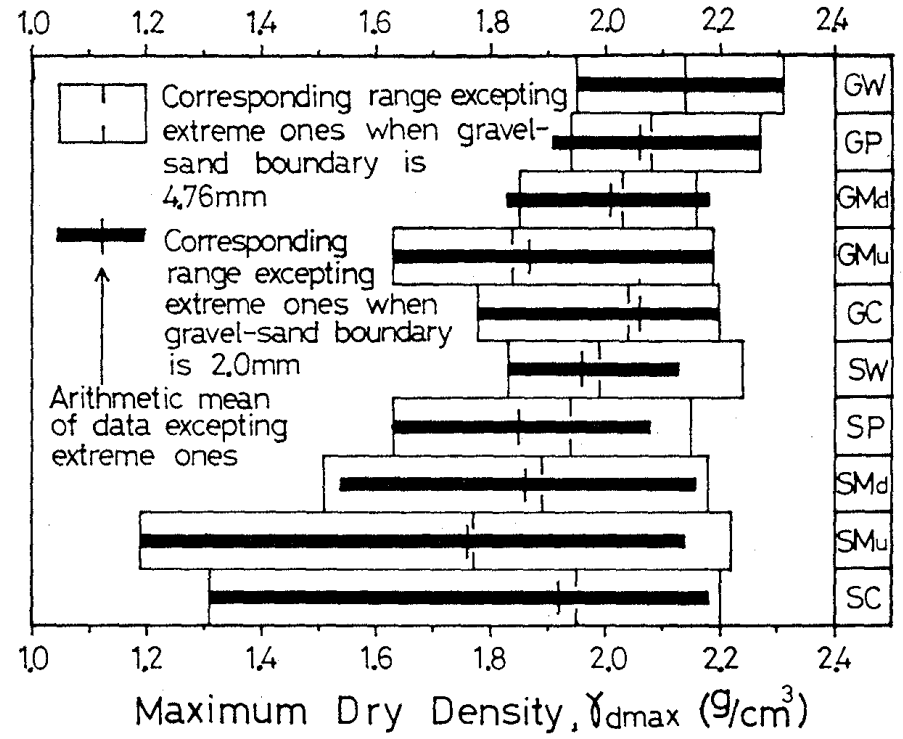

Fig. 3(b) Relationship between the Maximum Dry Density of the Modified AASHO Compaction Test and the Unified Soil Classification System 


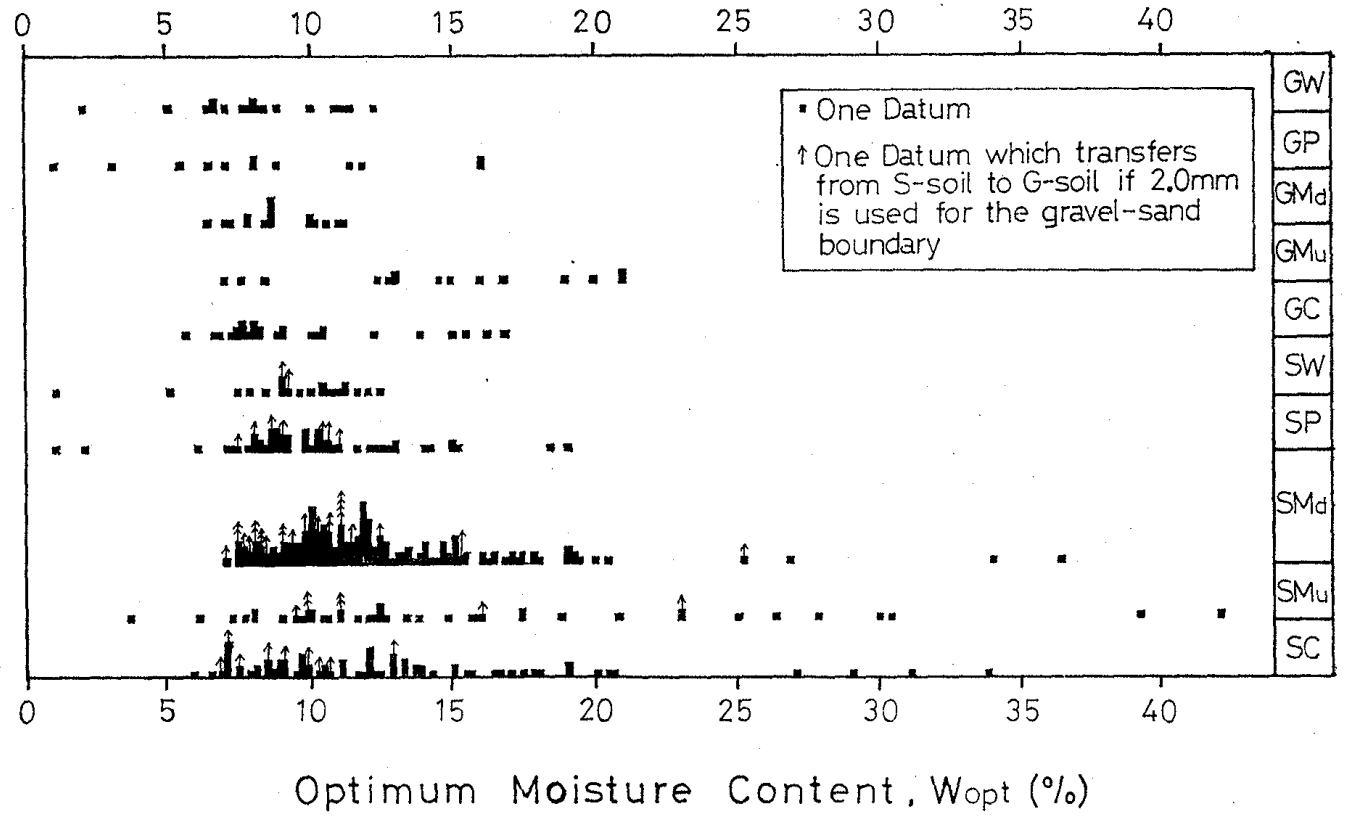

Fig. 4(a) Relationship between the Optimum Moisture Content of the Modified AASHO Compaction Test and the Unified Soil Classification System

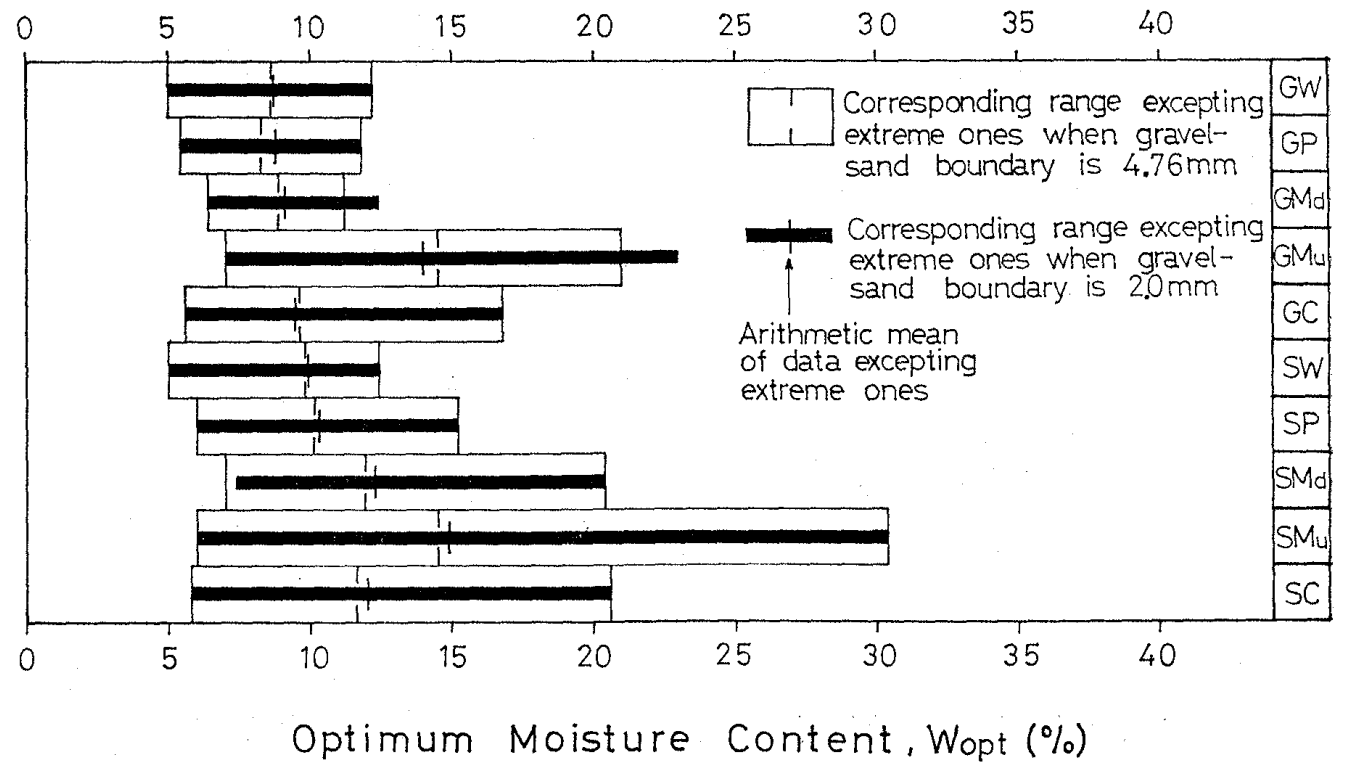

Fig. 4(b) Relationship between the Optimum Moisture Content of the Modified AASHO Compaction Test and the Unified Soil Classification System 


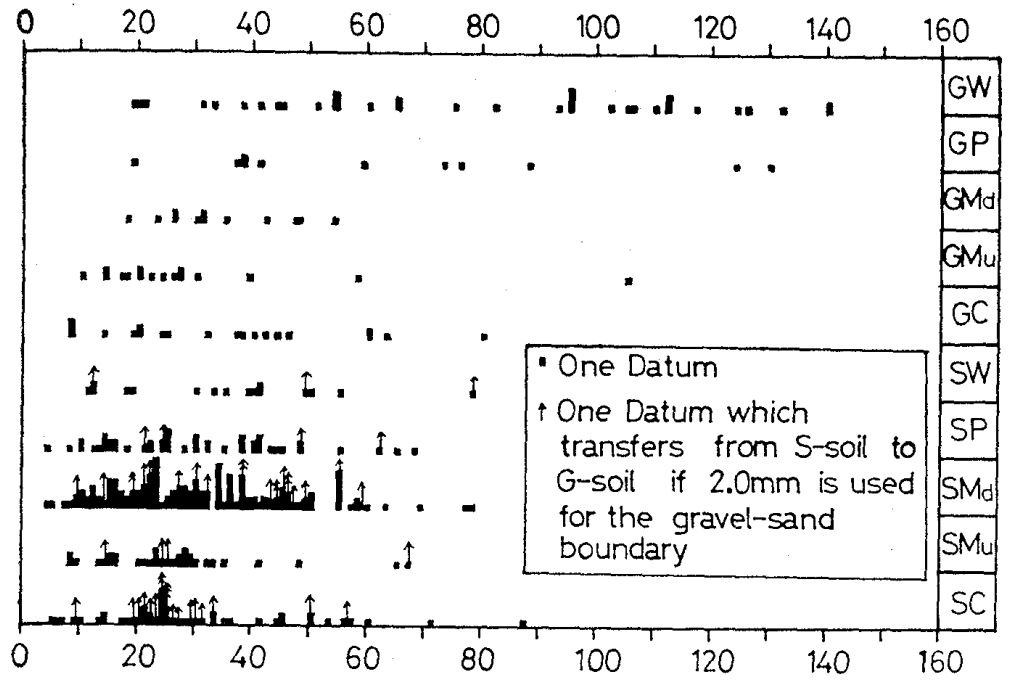

Soaked CBR at 95 Percent Density of the Maximum

Fig. 5(a) Relationship between the Soaked CBR at 95 Percent Density of the Maximum and the Unified Soil Classification System

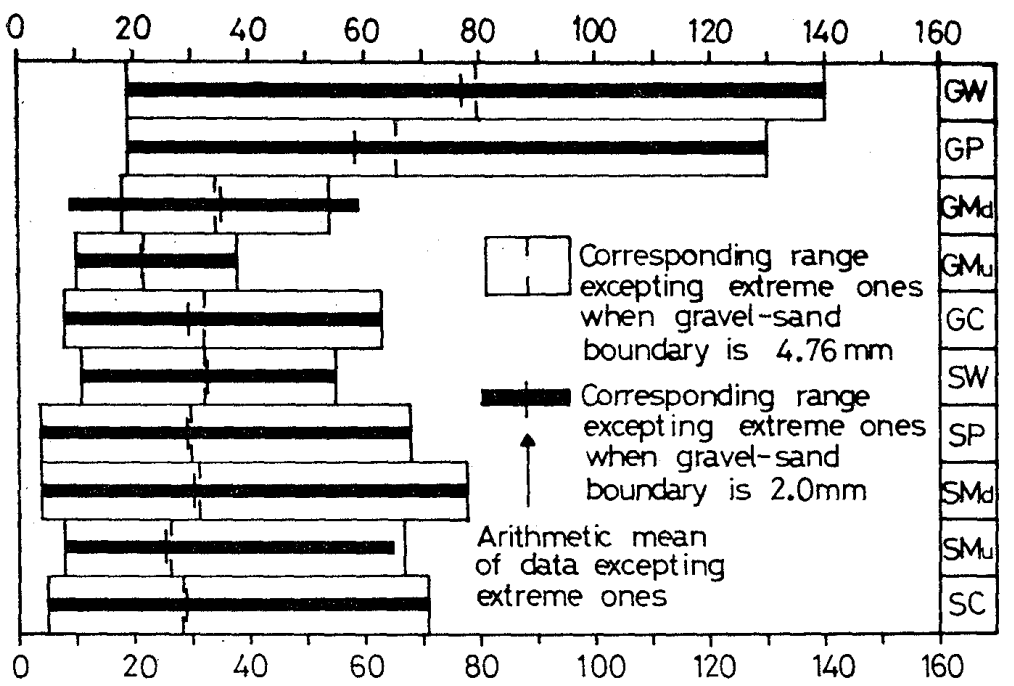

Soaked CBRat 95 Percent Density of the Maximum

Fig. 5(b) Relationship between the Soaked CBR at 95 Percent Density of the Maximum and the Unified Soil Classification System 


\section{CLASSIFICATION BASED ON CONTENT OF FINES}

In order to study the changes in the engineering properties with content of fines finer than $74 \mu$, the relations of the maximum dry density of the modified AASHO compaction test and the soaked CBR at 95 percent density of the maximum versus the content of fines are plotted in Figs. 6 and 7. There are wide ranges of the corresponding engineering properties in these figures. Such wide ranges of correspondence may be caused by the differences in nature of coarse materials and/or fines, and the gradation of particles. In Figs. 6 and 7, symbols corresponding to the USCS are used to show gravel or sand, well or poorly graded, and difference of fines.

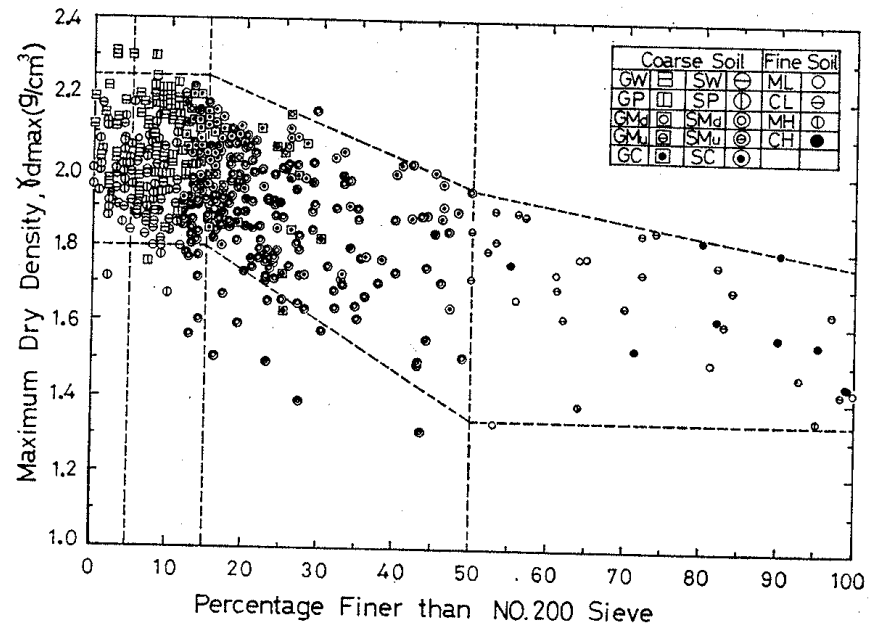

Fig. 6. Relations between the Maximum Dry Density of the Modified AASHO Compaction Test and Content of Fines

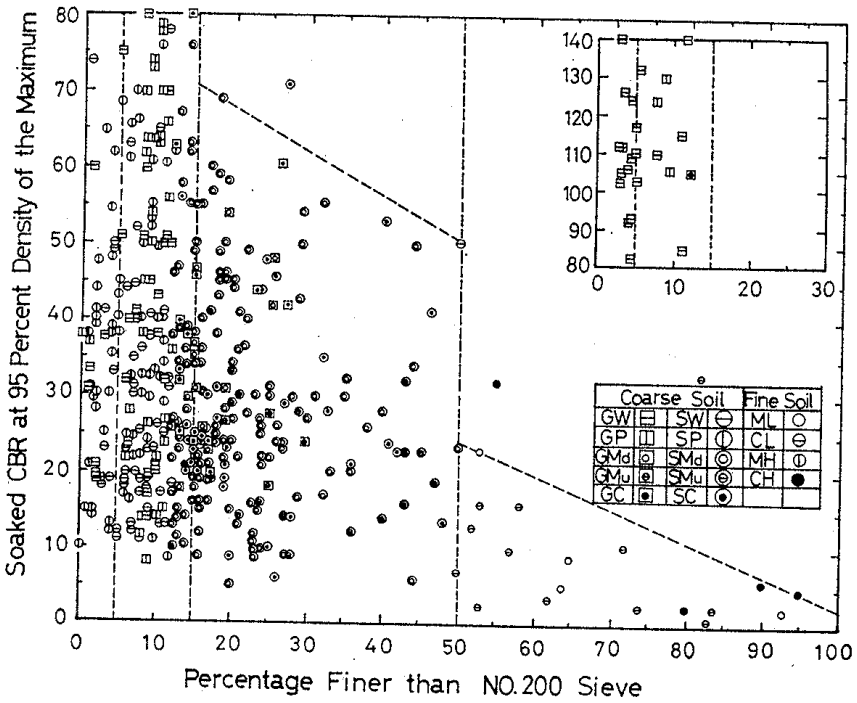

Fig. 7. Relations between the Soaked CBR at 95 Percent Density of the Maximum and Content of Fines 
In Fig. 6, the maximum dry density for the soils with fines of 0 to 15 percent by weight is $1.80 \mathrm{~g} / \mathrm{cm}^{3}$ to $2.25 \mathrm{~g} / \mathrm{cm}^{3}$. As content of fines increases more than 15 percent, the upper and lower limits of the maximum dry density go down, and the density is $1.35 \mathrm{~g} / \mathrm{cm}^{3}$ to $1.90 \mathrm{~g} / \mathrm{cm}^{3}$ for fine soils which have fines of more than 50 percent by weight. Similarly in Fig. 7, the upper limit of soaked CBR at 95 percent density of the maximum decreases as content of fines increases more than 15 percent. Fine soils which contain fines of more than 50 percent show the lower CBR values than the values of soils with fines of 15 to 50 percent. In Figs. 6 and 7, the values of gravels are relatively higher than the values of sands.

The changes in permeability with content of fines are also investigated. Fig. 8 shows the experimental results according to Barber and Sawyer (1952), Murao (1971) and the authors. The grading curves of samples used by Barber and Sawyer and the authors are shown in Fig. 9. The authors' permeability tests were performed at the maximum density of the standard AASHO compaction test.

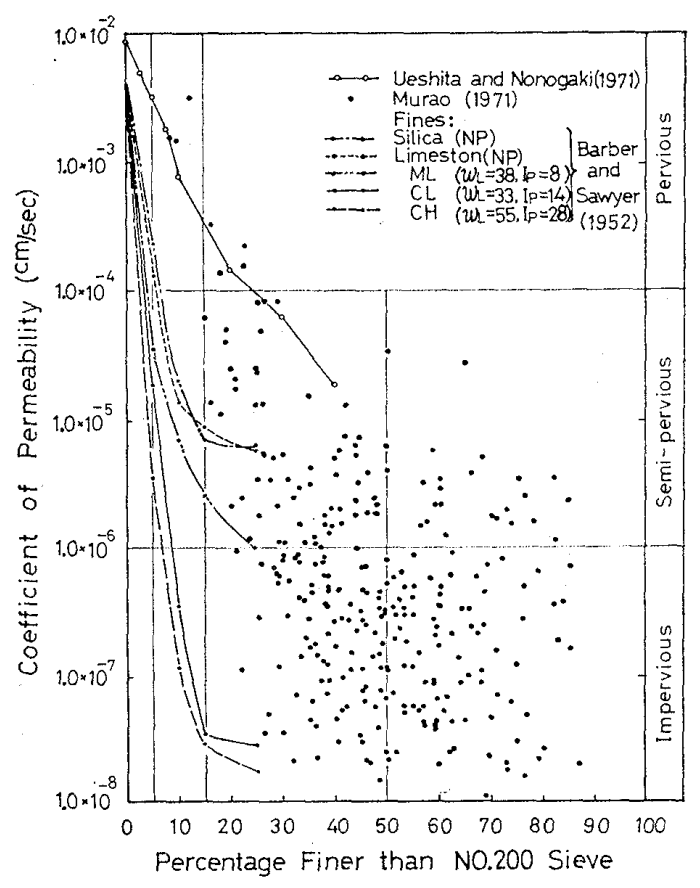

Fig. 8. Relations between the Coefficient of Permeability of Compacted Soils and Content of Fines

According to Fig. 8, 15 percent content of fines corresponds to a rough boundary between pervious and semi-pervious states. But, based on Barber and Sawyer's data, even 5 percent content of fines makes soil semi-pervious depending on the nature of fines and the gradation of aggregates. On the other hand, the compacted soils with fines more than 15 percent are semi-pervious or impervious materials.

Considering the above-mentioned data, $5 \%, 15 \%$ and $50 \%$ of fines may be used as the classification boundaries between clean gravels or sands, gravels or sands with some fines, 


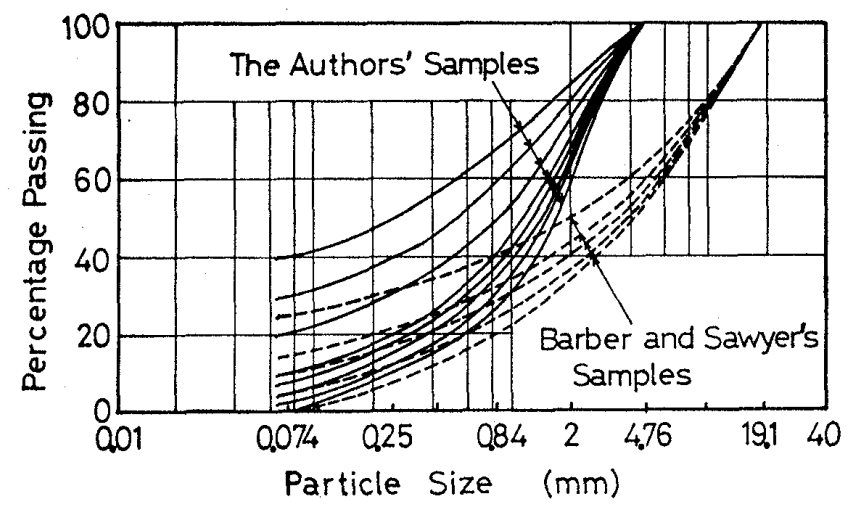

Fig. 9. Grading Curves of Samples used for Permeability Test

gravels or sands with fines, and fine soils based on engineering properties.

\section{CLASSIFICATION BETWEEN WELL-GRADED AND POORLY GRADED SOILS}

According to the USCS, the classification between well-graded gravels or sands and poorly graded ones is based on the coefficient of uniformity $C_{u}$ and the coefficient of curvature $C_{z}$ which are defined as follows:

$$
\begin{aligned}
C_{u} & =\frac{D_{60}}{D_{10}} \\
C_{z} & =\frac{\left(D_{30}\right)^{2}}{D_{10} \times D_{60}}
\end{aligned}
$$

where $D_{10}, D_{30}$ and $D_{60}$ are the particle-size diameters corresponding respectively to 10 , 30 and 60 percent passing on the cumulative particle-size distribution curve.

The criteria for well-graded gravels or sands are $C_{z}=1$ to 3 in all and $C_{u}>4$ for gravels or $C_{u}>6$ for sands in the USCS designated by ASTM, $C_{u}>5$ for gravels and sands in the suggested BSCS or $C_{u}>6$ for gravels and sands in DIN.

To investigate the effect of the coefficient of uniformity on engineering properties, the relations of the maximum dry density of the modified ASSHO compaction test and the soaked CBR values at 95 percent density of the maximum versus the coefficient of uniformity are plotted only for gravels and sands the coefficients of curvature of which are between 1 and 3, as shown in Figs. 10 and 11.

Although it is not easy to divide gravels and sands at a certain value of the coefficient of uniformity based on the engineering properties in Figs. 10 and $11, C_{u}$ of 10 may be used as the boundary between well-graded soils and poorly graded ones. According to Kishida (1969), the coarse-grained soils having the 50 percent size of less than $2.0 \mathrm{~mm}$ and the coefficient of uniformity of less than 10 have properties that can cause liquefaction under certain conditions.

Next, in order to consider the meaning of the coefficient of curvature, the relations of the maximum dry density of the modified AASHO compaction test and the soaked CBR 


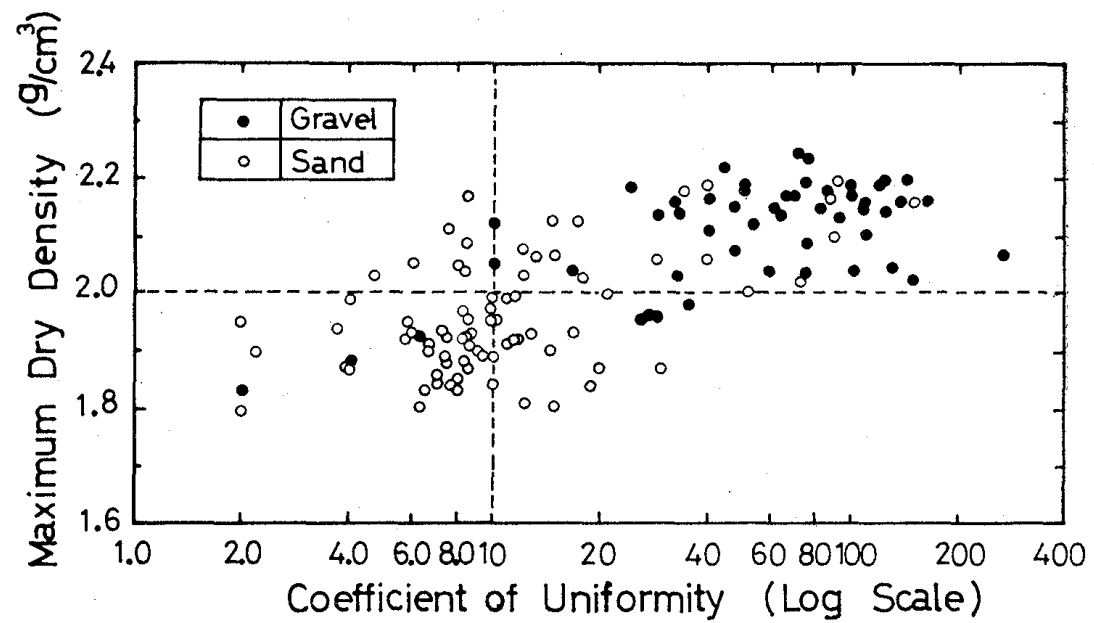

Fig. 10. Relations between the Maximum Dry Density of the Modified AASHO Compaction Test and Coefficient of Uniformity

(Only for Coefficient of Curvature between 1 and 3)

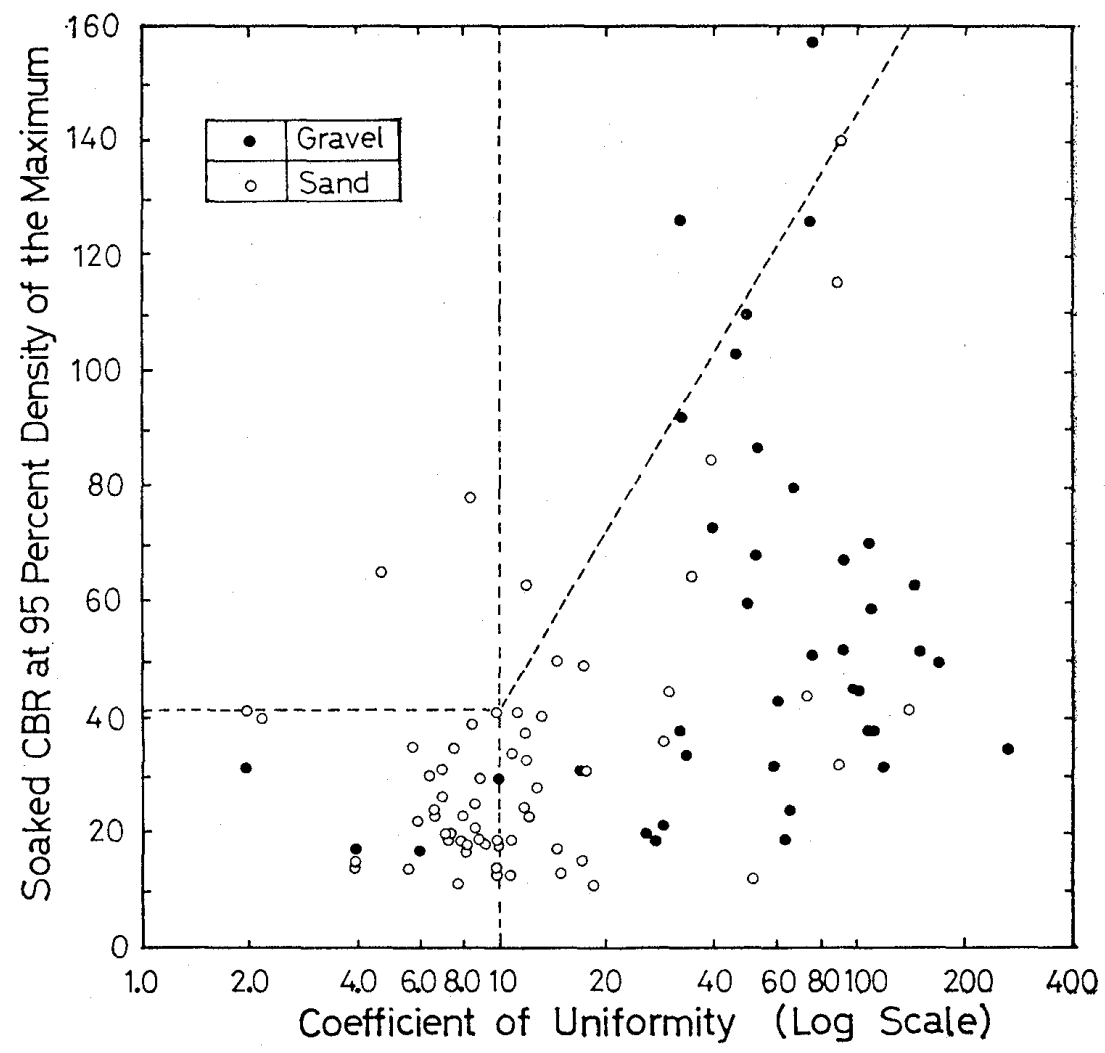

Fig. 11. Relations between the Soaked CBR at 95 Percent Density of the Maximum and Coefficient of Uniformity

(Only for Coefficient of Curvature between 1 and 3) 
at 95 percent density of the maximum versus the coefficient $C_{z}$ are plotted as shown in Figs. 12 and 13. In Fig. 12, the meaning of $C_{z}$ of 1 and 3 is not clear. In Fig. 13, a boundary is seen at $C_{z}=1$, but the meaning of $C_{z}=3$ is not clear.

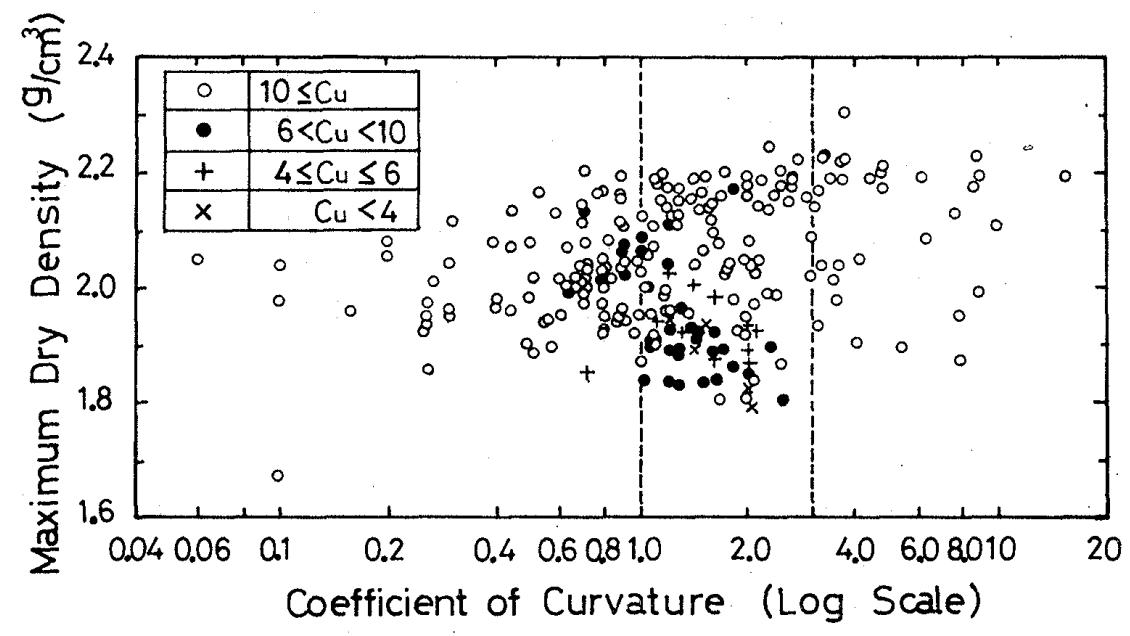

Fig. 12. Relations between the Maximum Dry Density of the Modified AASHO Compaction Test and Coefficient of Curvature (Gravels and Sands)

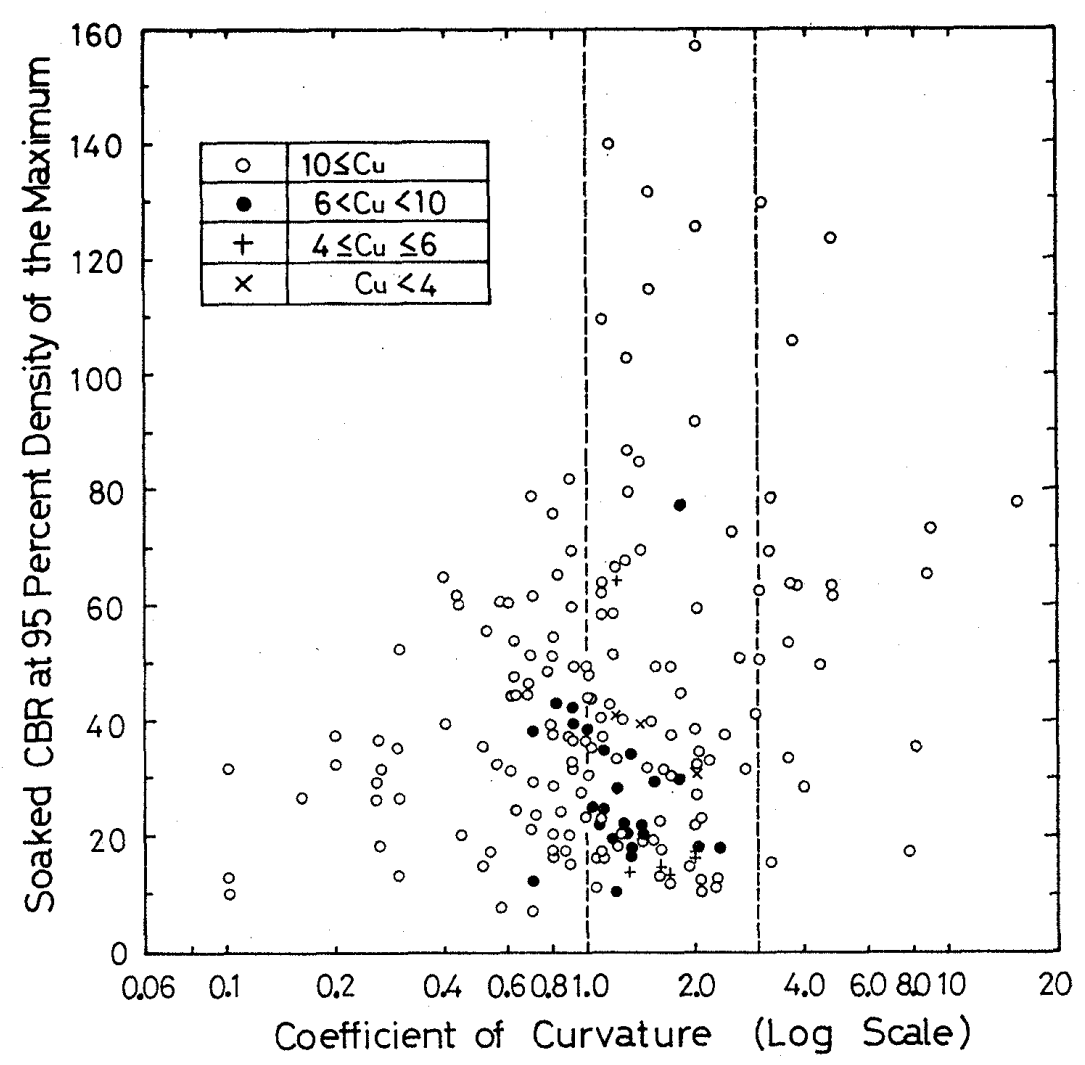

Fig. 13. Relations between the Soaked CBR at 95 Percent Density of the Maximum and Coefficient of Curvature (Gravels and Sands) 


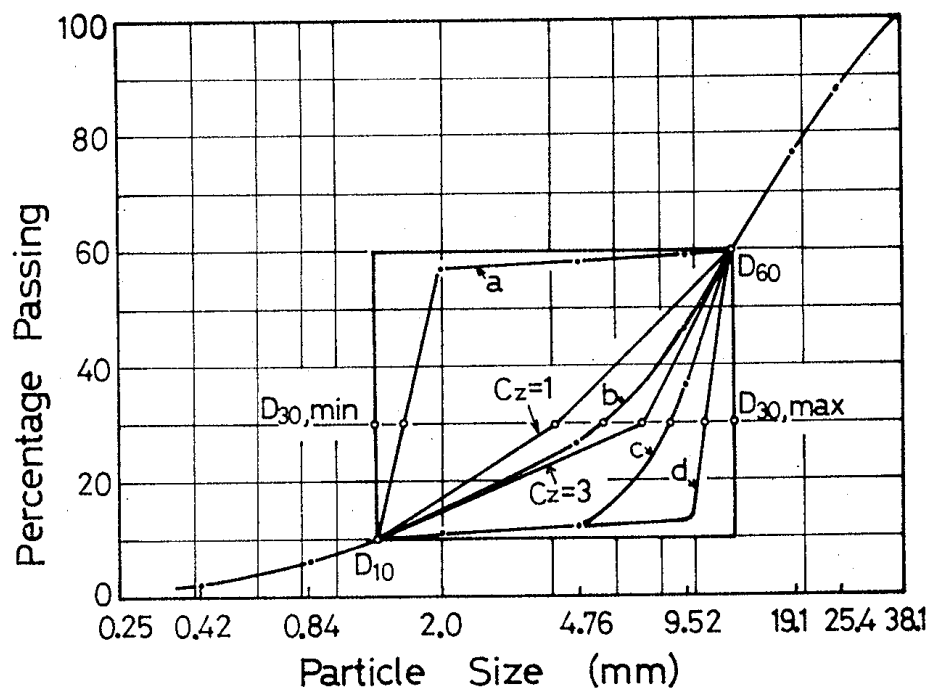

Fig. 14. Meaning of Coefficient of Curvature and Grading Curves of Experimental Samples used for Fig. 15 (Coefficient of Uniformity: 10)

Referring Fig. 14, it can be shown that the coefficient of $C_{z}$ is bound by the coefficient of $C_{u}$, and should be between $C_{z}$, min and $C_{z}$, max which are defined as follows:

$$
\begin{gathered}
C_{z, \min }=\frac{\left(D_{30, \mathrm{~min}}\right)^{2}}{D_{10} \times D_{60}}=\frac{\left(D_{10}\right)^{2}}{D_{10} \times D_{60}}=\frac{D_{10}}{D_{60}}=\frac{1}{C_{u}} \\
C_{z, \max }=\frac{\left(D_{30, \text { max }}\right)^{2}}{D_{10} \times D_{60}}=\frac{\left(D_{60}\right)^{2}}{D_{10} \times D_{60}}=\frac{D_{60}}{D_{10}}=C_{u}
\end{gathered}
$$

where $D_{30, \min }$ and $D_{30, \max }$ are the minimum and the maximum of $D_{30}$ for given $D_{10}$ and $D_{60}$, as shown in Fig. 14.

Considering this restriction, Figs. 12 and 13 are not reasonable because data having different values of $C_{u}$ are plotted on the same graphs. Therefore the relations are plotted for each set of $D_{60}$ and $C_{u}$ to investigate the effect of the coefficient of curvature on the engineering properties as shown in Figs. 15 and 16.

Based on Figs. 15 and 16, the criterion of the coefficient of curvature for well-graded soils may be revised as follows:

$$
1<C_{z}<\sqrt{C_{u}}
$$

$C_{z}=1$ is the center point of $C_{z, \min }$ and $C_{z, \max }$ on the logarithmic scale, and $C_{z}=$ $\sqrt{C_{u}}$ is again the center point of $C_{z}=1$ and $C_{z}$, max on the logarithmic scale.

Therefore, to judge the grading curves, the following criteria may be appropriate.

$C_{u}<10$ : Poorly graded with a uniform (i.e. narrow) grading.

$C_{z}<1$, or $C_{z}>\sqrt{C_{u}}$ : Poorly graded with a gap grading.

$C_{u}>10$

$\left.1<C_{z}<\sqrt{C_{u}}\right\}$ : Well graded 

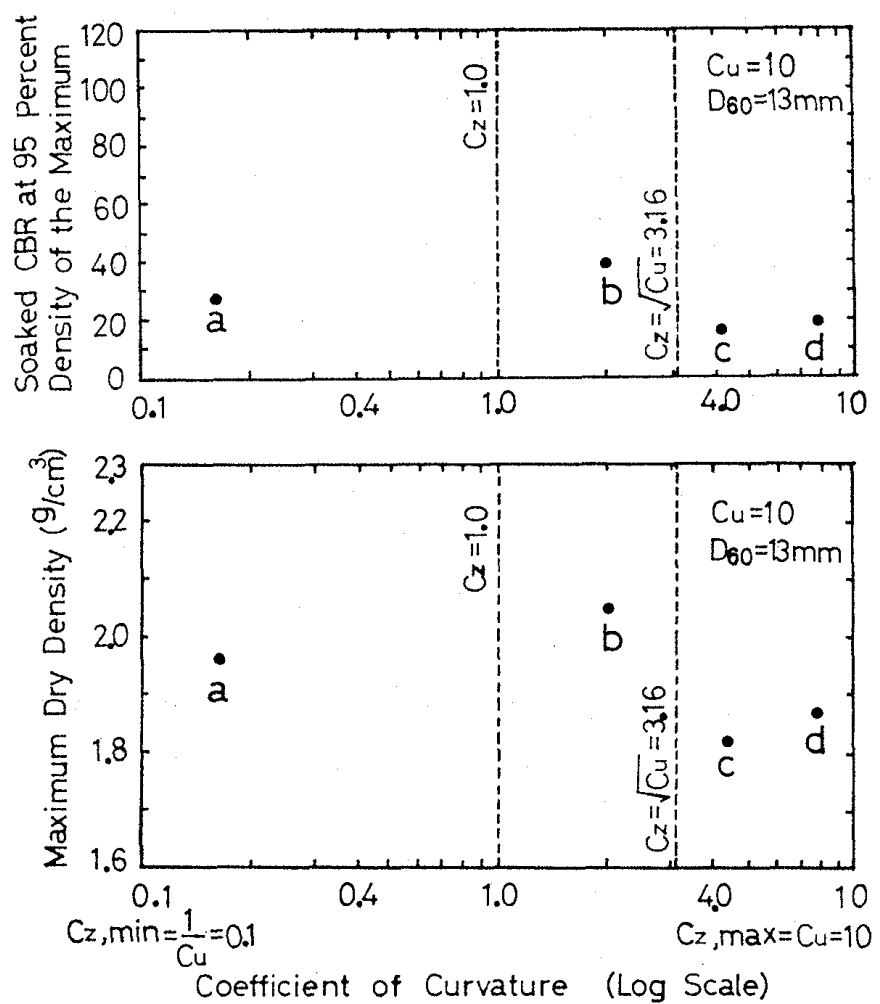

Fig. 15. Relations of the Maximum Dry Density of the Modified AASHO Compaction Test and the.'Soaked CBR at 95 Percent Density of the Maximum versus Coefficient of Curvature $\left(\mathrm{D}_{60}=13 \mathrm{~mm}, \mathrm{Cu}=10\right)$
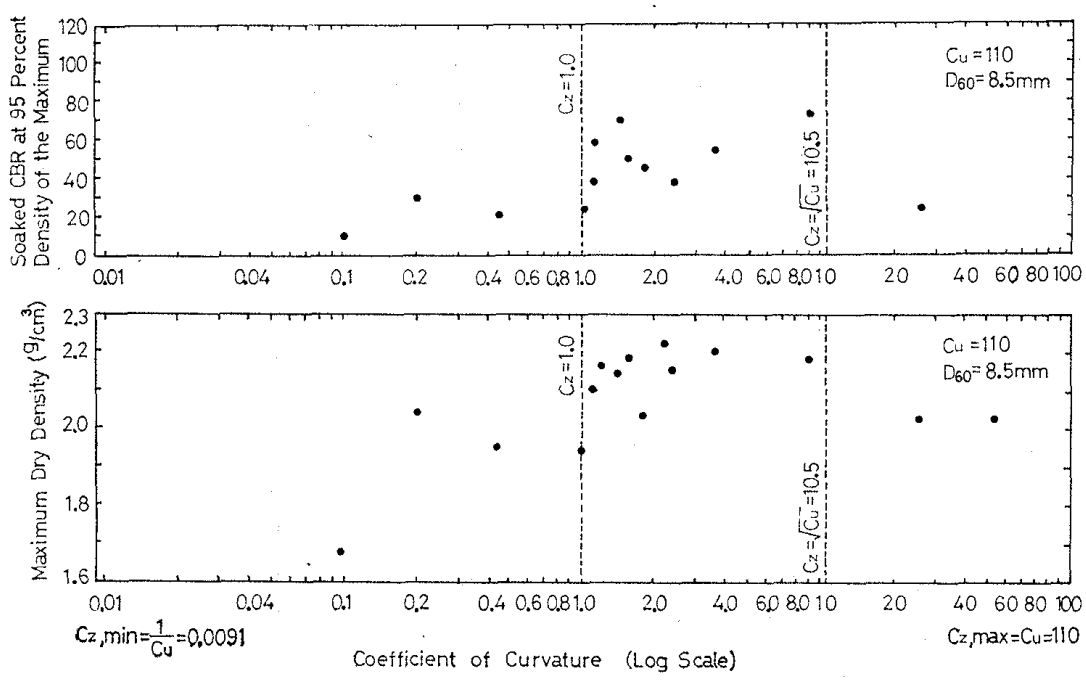

Fig. 16. Relations of the Maximum Dry Density of the Modified AASHO Compaction Test and the Soaked CBR at 95 Percent Density of the Maximum versus Coefficient of Curvature $\left(D_{60}=8.5 \mathrm{~mm}, \mathrm{Cu}=110\right)$ 
Concerning the ideal grading curve, there was a proposition by Fuller and Thompson (1907) as shown by the following equation:

$$
p=100\left(\frac{D_{p}}{D_{\max }}\right)^{n}
$$

where $D_{p}$ represents the particle size in question, $p$ is the percent by weight finer than that particle size, and $D_{\max }$ is the maximum size of aggregate. Primarily, equation (6) was proposed with $n=0.5$ for concrete aggregates. Afterwards, Lee (1938) proposed $n=0.25$ to 0.5 for coarse materials of fill dam construction. Concerning the coefficients of $C_{u}$ and $C_{z}$ of these grading curves, $C_{u}=1296$ to 36 and $C_{z}=5.06$ to 2.25 for $n=0.25$ to 0.5 . This range of the grading curve proposed by Lee is included within the range of well-graded soils according to the authors' criteria, but corresponding partly to the poorly graded, according to the usual criteria of $C_{z}=1$ to 3 for well-graded.

\section{DISCUSSION ON A MODIFIED CLASSIFICATION SYSTEM FOR COARSE SOILS}

Based on the above-mentioned considerations, the authors propose a modified classification system of the USCS for coarse soils as shown in Fig. 17. In this modification, $2.0 \mathrm{~mm}$ is adopted as the gravel-sand boundary considering international and intersociety tendencies and the prevailing practice in Japan. Symbol Md means desirable M-fines and symbol $\mathrm{Mu}$ means undesirable $\mathrm{M}$-fines which are corresponding to silty, organic, volcanic or clayey fines. If possible, it may be preferable to classify $\mathrm{Mu}$ into $\mathrm{M}$ for

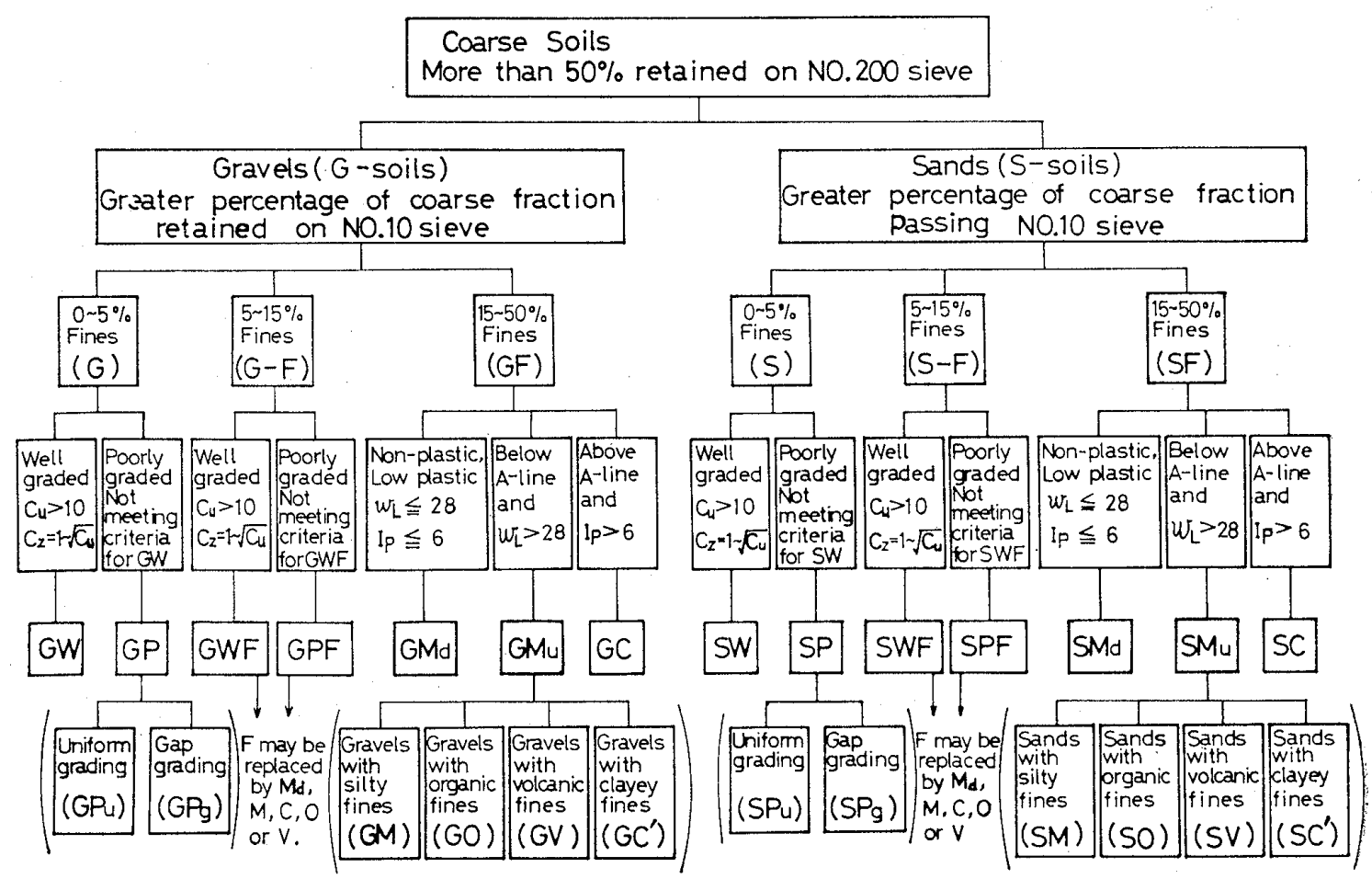

Fig. 17. Suggested Classification System for Coarse Soils 


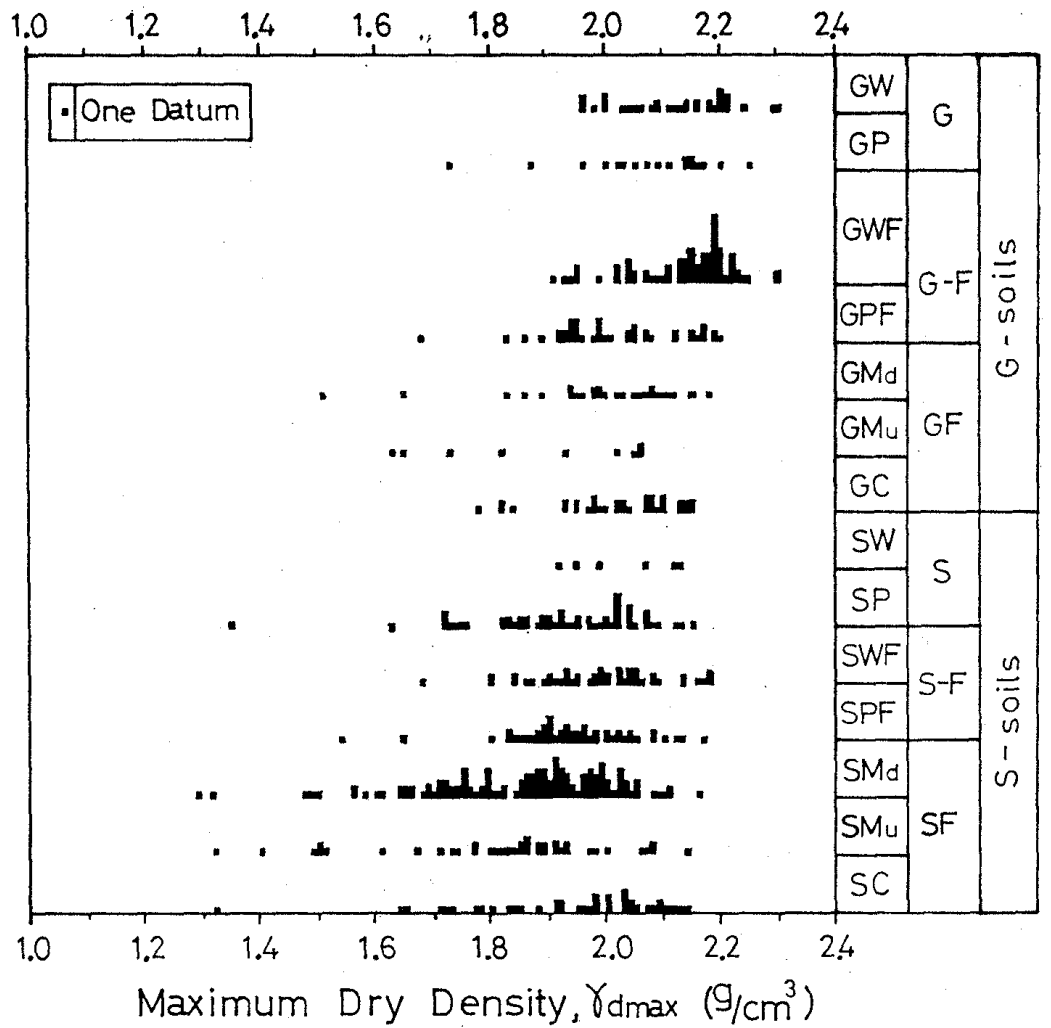

Fig. 18(a). Relationship between the Maximum Dry Density of the Modified AASHO Compaction and the Suggested Classification System

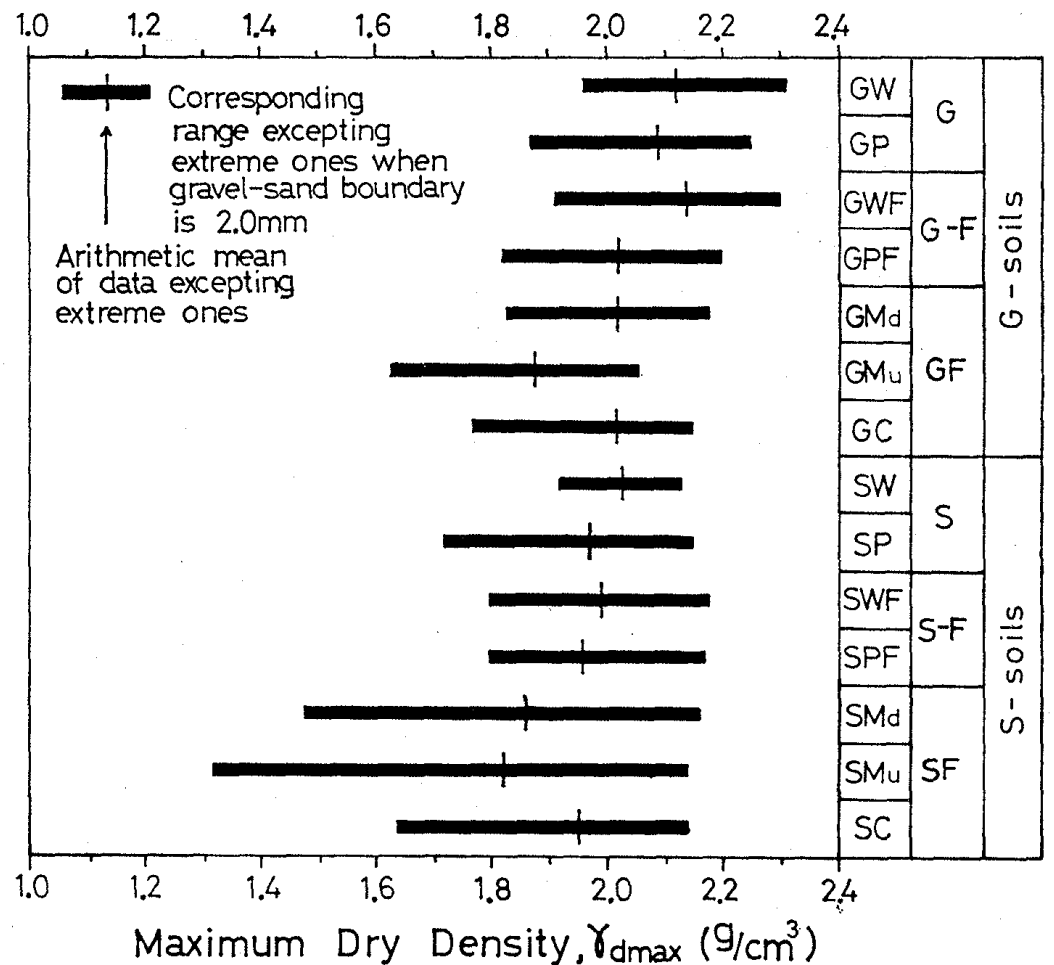

Fig. 18(b). Relationship between the Maximum Dry Density of the Modified AASHO Compaction and the Suggested Classification System 
silty fines, $\mathrm{O}$ for organic fines, $\mathrm{V}$ for volcanic fines and $\mathrm{C}^{\prime}$ for clayey fines, even though it is impossible to do so herein for lack of details of data.

Borderline classifications between clean gravels or sands (GW, GP, SW or SP) and gravels or sands with fines (GM, GC, SM or SC) in the USCS are reperceived as important soil groups symboled by G-F or S-F (GWF, GPF, SWF or SPF, if possible and necessary), and the criterion, 5 to 12 percent of fines in the USCS, is revised into 5 to 15 percent of fines for these soil groups.

Using this modified classification system, the relations between the compaction pro-

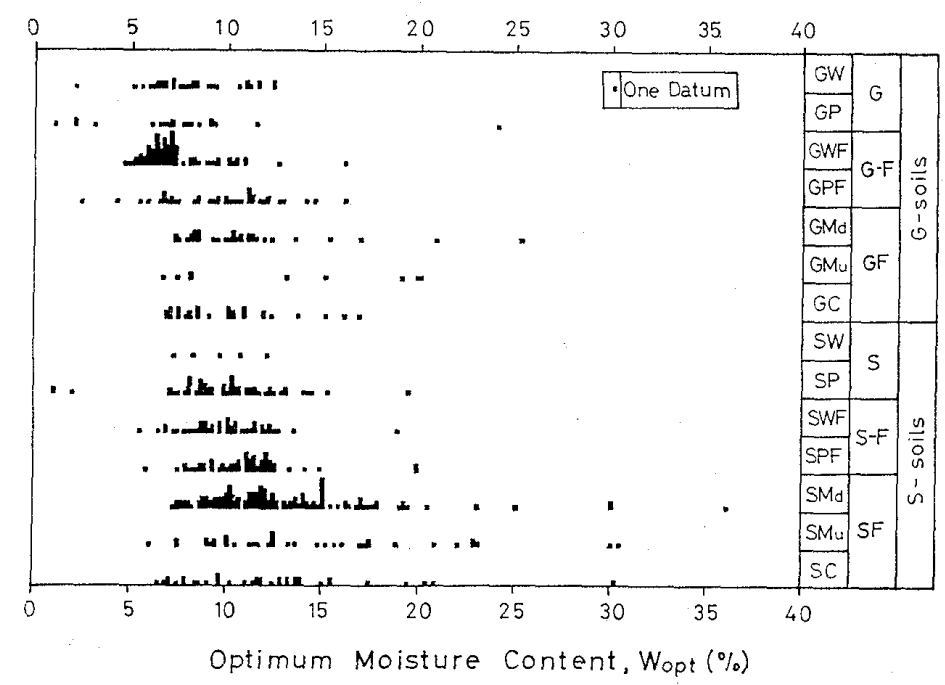

Fig. 19(a). Relationship between the Optimum Moisture Content of the Modified AASHO Compaction Test and the Suggested Classification System

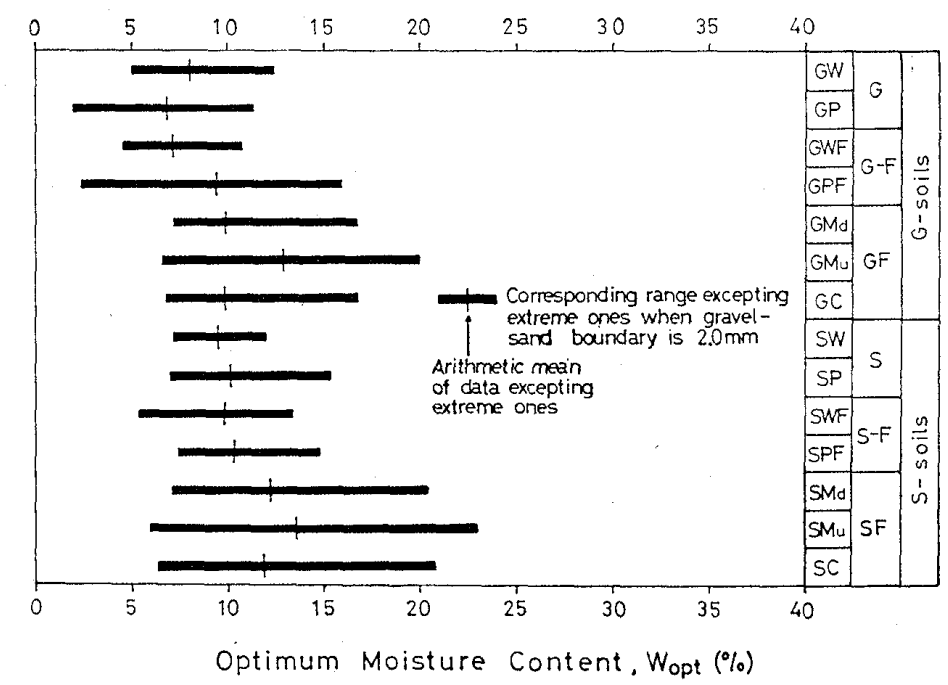

Fig. 19(b). Relationship between the Optimum Moisture Content of the Modified AASHO Compaction Test and the Suggested Classification System 
perties or the soaked CBR values at 95 percent density of the maximum and soil groups are plotted as shown in Figs. 18, 19 and 20.

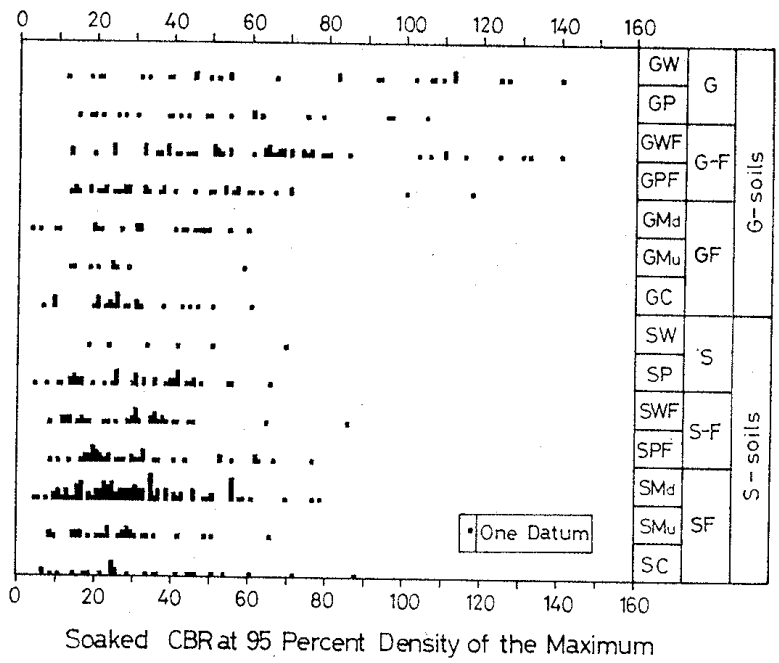

Fig. 20(a). Relationship between the Soaked CBR at 95 Percent Density of the Maximum and the Suggested Classification System

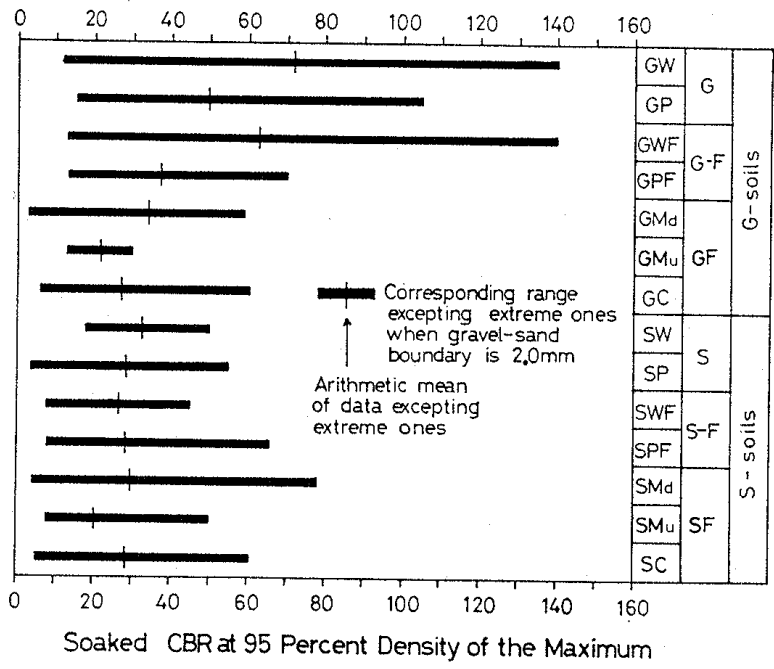

Fig. 20(b). Relationship between the Soaked CBR at 95 Percent Density of the Maximum and the Suggested Classification System

If it is convenient to use a simplified classification system, only 6 groups, i.e. G, G-F, GF, S, S-F, and SF, can be used instead of 14 groups as easily understood in Fig. 17. 


\section{CONCLUSIONS}

The classification system for coarse soils was studied based on the maximum dry density and the optimum moisture content of the modified AASHO compaction test, the soaked CBR at 95 percent density of the maximum, and the coefficient of permeability of compacted soils. According to this study, the following criteria for classification were drawn.

Soils may be classified by the proportion of fines as follows:

$0-5$ percent fines: Clean gravels or sands $(\mathrm{G}, \mathrm{S})$

5-15 percent fines: Gravels or sands with some fines (G-F, S-F)

15-50 percent fines: Gravels or sands with fines (GF, SF)

50-100 percent fines: Fine soils (F)

Gravels and sands may be classified by the coefficient of uniformity $C_{u}$ and the coefficient of curvature $C_{z}$ as follows:

$C_{u}<10$ : Poorly graded with a uniform grading (GPu, SPu)

$C_{z}<1$, or $C_{z}>\sqrt{C_{u}}$ : Poorly graded with a gap grading (GPg, SPg)

$C_{u}>10$, and $1<C_{z}<\sqrt{C_{u}}$ : Well graded (GW, SW)

Fines (F) may be classified into desirable M-fines (Md), undesirable $\mathrm{M}$-fines $(\mathrm{Mu})$ and clayey fines $(\mathrm{C})$ as follows:

$w_{L} \leqq 28$ and $I_{P} \leqq 6:$ Desirable M-fines $(\mathrm{Md})$

$I_{P}<0.73\left(w_{L}-20\right)$ and $w_{L}>28:$ Undesirable M-fines $(\mathrm{Mu})$

$I_{P} \geqq 0.73\left(w_{L}-20\right)$ and $I_{P}>6$ : Clayey fines $(\mathrm{C})$

If necessary and possible, $\mathrm{Mu}$ may be furthermore classified into four groups as follows:

$$
\mathrm{Mu}= \begin{cases}\mathrm{M}: & \text { Silty fines } \\ \mathrm{O}: & \text { Organic fines } \\ \mathrm{V}: & \text { Volcanic fines } \\ \mathrm{C}^{\prime}: & \text { Clayey fines }\end{cases}
$$

Finally, the authors proposed a modified USCS using the above-mentioned criteria and $2.0 \mathrm{~mm}$ for the gravel-sand boundary, and showed the relationships of the modified classification system versus the maximum dry density and the optimum moisture content of the modified AASHO compaction test, and the soaked CBR at 95 percent of the maximum dry density.

\section{ACKNOWLEDGEMENTS}

The authors wish to express their gratitude to Mr. T. Asai who contributed to this paper in experimental works and analyses of data. They are grateful to Mr. M. Matsui of the Laboratory of Japan Highway Public Corporation, for providing many data which were used in this paper. They also wish to acknowledge helpful discussions with Prof. G. Miki, Dr. G. Yamada and the members of the Committee on Standardization of Identification and Classification of Soils, Japanese Society of Soil Mechanics and Foundation Engineering. 


\section{NOTATION}

The following symbols are used in this paper:

AASHO = American Association of State Highway Officials;

ASTM $=$ American Society for Testing and Materials;

$\mathrm{C}=$ clayey fines, plasticity of which is $I_{P} \geqq 0.73\left(w_{L}-20\right)$ and $I_{P}>6$;

$\mathrm{C}^{\prime}=$ clayey fines, plasticity of which is $I_{P}<0.73\left(w_{L}-20\right)$ and $w_{L}>28$;

$\mathrm{CBR}=$ California Bearing Ratio;

$C_{u}=$ coefficient of uniformity;

$C_{z}=$ coefficient of curvature;

$C_{z, \min }=$ the minimum value of $C_{z}$ for a given $C_{u}$, which is equal to $1 / C_{u}$;

$C_{z, \max }=$ the maximum value of $C_{z}$ for a given $C_{u}$, which is equal to $C_{u}$;

$D_{10}=$ particle-size diameter corresponding to 10 percent passing on the grading curve;

$D_{30}=$ particle-size diameter corresponding to 30 percent passing on the grading curve;

$D_{60}=$ particle-size diameter corresponding to 60 percent passing on the grading curve;

$D_{30, \min }=$ the minimum value of $D_{30}$ for given $D_{10}$ and $D_{60}$;

$D_{30, \max }=$ the maximum value of $D_{30}$ for given $D_{10}$ and $D_{60}$;

$D_{\max }=$ the maximum particle-size diameter;

$D_{p}=$ particle-size diameter corresponding to $p$ percent passing on the grading curve;

$\mathrm{DIN}=$ Deutsche Industrie-Norm;

$F=$ fines (passing No. 200 sieve)

$\mathrm{G}=$ gravel, greater proportion of coarse fraction is of gravel size (retained on No. 10 sieve, in the suggested classification system);

$\mathrm{GC}=$ gravel with clayey fines, plasticity of which is $I_{P} \geqq 0.73\left(w_{L}-20\right)$ and $I_{P}>6$;

$\mathrm{GC}^{\prime}=$ gravel with clayey fines, plasticity of which is $I_{P}<0.73\left(w_{L}-20\right)$ and $w_{L}>28$ (in the suggested classification system);

$\mathrm{GF}=$ gravel with fines (in the simplified classification system);

$\mathrm{G}-\mathrm{F}=$ gravel with some fines (in the simplified classification system);

$\mathrm{GM}=$ gravel with silty fines;

$\mathrm{GMd}=$ gravel with desirable M-fines, plasticity of which is $w_{L} \leqq 28$ and $I_{P}$ $\leqq 6$;

$\mathrm{GMu}=$ gravel with undesirable M-fines, plasticity of which is $I_{P}<0.73\left(w_{L}-20\right)$ and $w_{L}>28$;

$\mathrm{GO}=$ gravel with organic fines;

$\mathrm{GP}=$ poorly graded gravel;

$\mathrm{GPg}=$ gap-graded gravel;

$\mathrm{GPu}=$ uniformly graded gravel;

$\mathrm{GPF}=$ poorly graded gravel with some fines; 


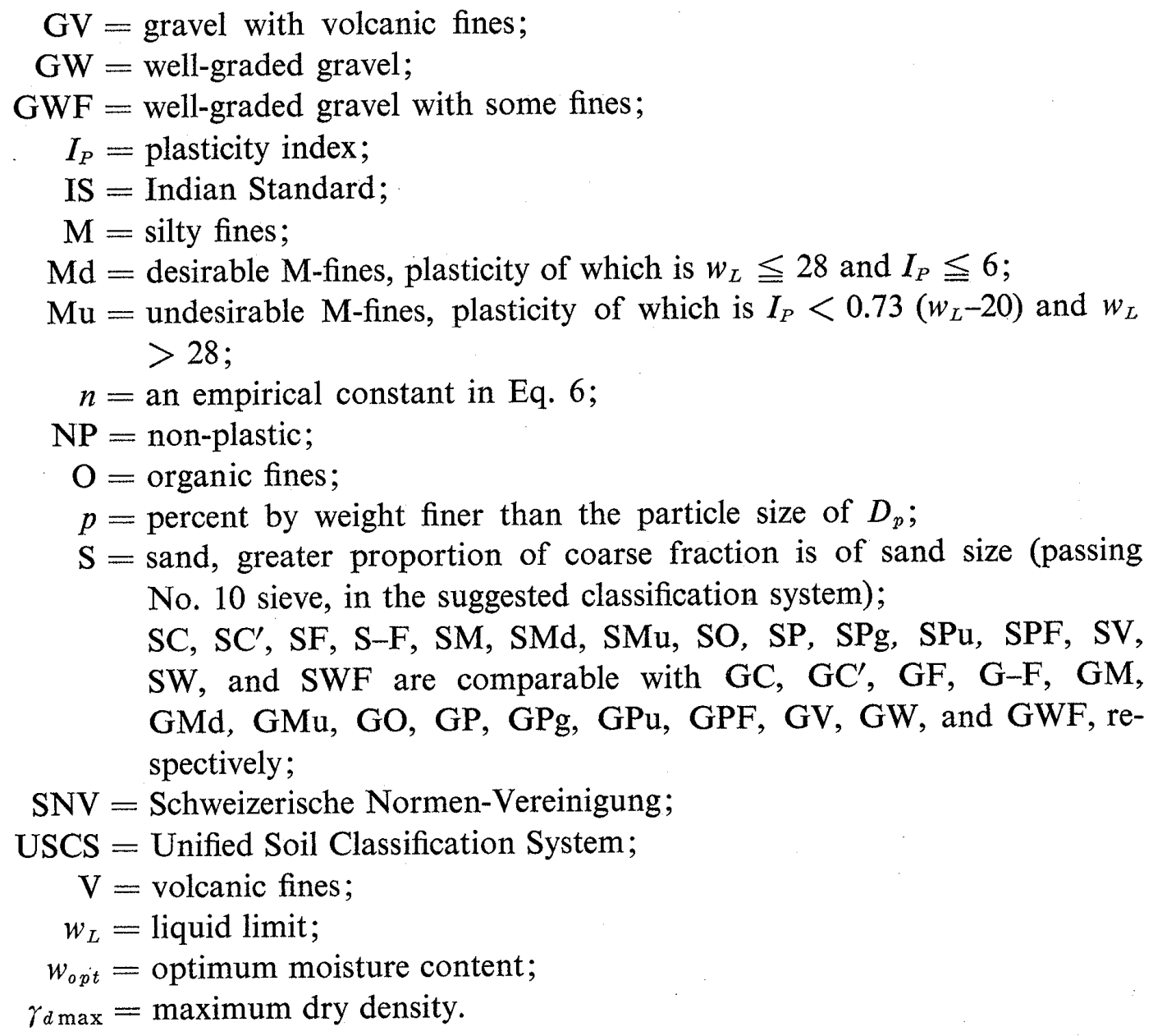

\section{REFERENCES}

American Society for Testing and Materials (1970): Standard Method for Classification of Soils for Engineering Purposes, ASTM Designation: D2487-69, 1970 Book of ASTM Standards, Part 11, pp. 777-782.

Association Suisse de Normalisation (1959): SNV 70005 and SNV 70008 . Soil Classification, Zurich. Barber, E. S. and Sawyer, C. L. (1952): Highway Subdrainage, Proc. of Highway Research Board, Vol. 31, pp. 643-666.

Casagrande, A. (1948): Classification and Identification of Soils, Trans. ASCE, Vol. 113, pp. 901-991.

Committee on Soil Properties of the Soil Mechanics and Foundations Division (1969): Standardization of Particle-Size Ranges, Proc. ASCE, Vol. 95, No. SM5, pp. 1247-1252.

Deutscher Normenausschuß (1970): Bodenklassifikation für bautechnische Zwecke und Methoden zum Erkennen von Bodengruppen, DIN 18196 (Juni 1970), Berlin.

Dumbleton, M. J. (1968): The Classification and Description of Soils for Engineering Purposes: A Suggested Revision of the British System, R.R.L. Report LR 182, Road Research Laboratory, Ministry of Transport.

Imai, S. (1970): Relationship between CBR and Particle Size of Crushed Stone, Data for the Committee on Standardization of Identification and Classification of Soils, Japanese Society of S.M.F.E., No. 45-25 (In Japanese). 
Indian Standards Institution (1959): Classification and Identification of Soils for General Engineering Purposes, IS: 1498-1959, New Delhi.

Kishida, H. (1969): Characteristics of Liquefied Sands during Mino-Owari, Tohnankai and Fukui Earthquakes, Soils and Foundations, Vol. 9, No. 1, pp. 75-92.

Köster, E. (1960): Mechanische Gesteins und Bodenanlyse Leitfaden der Granulometrie und Morphometrie, Carl Hanser Verlag, München.

Fuller, W. B. and Thompson, S. E. (1907): The Laws of Proportioning Concrete, Trans. ASCE, Vol. 59, pp. 67-143.

Lee, C. H. (1938): Selection of Materials for Rolled-Fill Earth Dams, Trans. ASCE, Vol. 103, pp. 1-18.

Murao, S. (1971): Relationship between Coefficient of Permeability and Percentage of Fines of Compacted Soils, Data for the Committee on Standardization of Identification and Classification of Soils, Japanese Society of S.M.F.E., No. 45-68 (In Japanese).

Ueshita, K. and Nonogaki, K. (1971): Considerations on the Unified Soil Classification of Fine-Grained Soils and Sandy Soils in the Tökai District, Japan, Trans. Japan Society of Civil Engineers, Vol. 2, Part 2.

Wagner, A. A. (1957): The Use of the Unified Soil Classification System by the Bureau of Reclamation, Proc. 4th Int. Conf. on S.M.F.E., Vol. 1, pp. 125-134.

(Received May 13, 1971) 